\title{
LATERAL FLOW ASSAY FOR CRYPTOCOCCAL ANTIGEN: AN IMPORTANT ADVANCE TO IMPROVE THE CONTINUUM OF HIV CARE AND REDUCE CRYPTOCOCCAL MENINGITIS-RELATED MORTALITY
}

\author{
Jose E. VIDAL(1,2) \& David R. BOULWARE(3)
}

\begin{abstract}
SUMMARY
AIDS-related cryptococcal meningitis continues to cause a substantial burden of death in low and middle income countries. The diagnostic use for detection of cryptococcal capsular polysaccharide antigen $(\mathrm{CrAg})$ in serum and cerebrospinal fluid by latex agglutination test (CrAg-latex) or enzyme-linked immunoassay (EIA) has been available for over decades. Better diagnostics in asymptomatic and symptomatic phases of cryptococcosis are key components to reduce mortality. Recently, the cryptococcal antigen lateral flow assay (CrAg LFA) was included in the armamentarium for diagnosis. Unlike the other tests, the CrAg LFA is a dipstick immunochromatographic assay, in a format similar to the home pregnancy test, and requires little or no lab infrastructure. This test meets all of the World Health Organization ASSURED criteria (Affordable, Sensitive, Specific, User friendly, Rapid/robust, Equipmentfree, and Delivered). CrAg LFA in serum, plasma, whole blood, or cerebrospinal fluid is useful for the diagnosis of disease caused by Cryptococcus species. The CrAg LFA has better analytical sensitivity for $C$. gattii than CrAg-latex or EIA. Prevention of cryptococcal disease is new application of CrAg LFA via screening of blood for subclinical infection in asymptomatic HIV-infected persons with $\mathrm{CD} 4$ counts $<100$ cells $/ \mu \mathrm{L}$ who are not receiving effective antiretroviral therapy. CrAg screening of leftover plasma specimens after CD4 testing can identify persons with asymptomatic infection who urgently require pre-emptive fluconazole, who will otherwise progress to symptomatic infection and/or die.
\end{abstract}

KEYWORDS: Cryptococcal meningitis; Cryptococcus; Diagnosis; Lateral flow assay.

\section{INTRODUCTION}

Cryptococcosis is a disease produced by species of Cryptococcus, which are unique in their capsular polysaccharides. This feature has been targeted for developing diagnostic tests that identify cryptococcal antigen (CrAg) (KOZEL \& BAUMAN, 2012). Globally, most cases of cryptococcosis are caused by Cryptococcus neoformans (serotypes A and D). C. neoformans var. grubii (serotype A) has a worldwide distribution and accounts for more than $90 \%$ of all cases of cryptococcosis, particularly in persons with acquired immunodeficiency syndrome (AIDS) (LITVINTSEVA et al., 2011). C. neoformans var. neoformans (serotype D) also has a global distribution, but clinical cases are concentrated in Europe. C. gattii (serotypes B and C), has traditionally been recognized a "tropical or subtropical fungus". The spread of $C$. gattii infection into new geographic areas was heralded by an ongoing outbreak that began in Vancouver Island, Canada and then was observed in other regions of British Columbia and the northwestern United States. Historically, our understanding is that C. gattii causes disease predominantly in persons with apparently "normal" immune system. However, more recently, new risk groups have been recognized, including patients with human immunodeficiency virus (HIV) and other immunodeficiencies, particularly auto-antibodies against granulocytemacrophage colony stimulating factor (GM-CSF) (CHEN et al., 2014).

Here, we will review the epidemiology of the current scenario of cryptococcal meningitis in HIV-infected persons, the strategies to reduce mortality and morbidity due to AIDS-related cryptococcal meningitis, and how CrAg lateral flow assay (CrAg LFA) can be useful in this context.

Global burden of cryptococcal meningitis in HIV-infected patients

AIDS-related cryptococcal meningitis causes approximately $15 \%$ of AIDS-related mortality annually (PARK et al., 2009). Sub-Saharan Africa has the highest burden, where Cryptococcus is the most common cause of adult meningitis (JARVIS et al., 2010; RAJASINGHAM et al., 2015), but Latin America is the third global region with most cases with 54,400 estimated cryptococcal meningitis cases annually in 2008 (PARK et al., 2009). More recent 2015 estimates of cryptococcal meningitis incidence in Latin America are approximately 10,000 cases annually (RAJASINGHAM, unpublished data).

There has been a massive expansion of access to antiretroviral therapy 


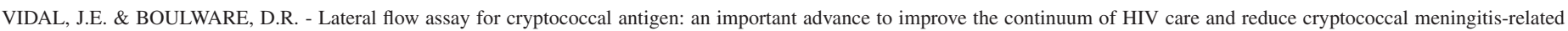
mortality. Rev. Inst. Med. Trop. Sao Paulo, 57(Suppl 19): 38-45, 2015.

(ART) in Latin America. AIDS-associated cryptococcal meningitis has decreased dramatically in the ART era (GUIMARÃES 2000; MIRZA et al., 2003; DROMER et al., 2004; JARVIS \& HARRISON, 2007; GRECO \& SIMAO, 2007). However, the impact of ART in reducing cryptococcosis appears to be less in low and middle-income countries with suboptimal access to ART.

\section{Mortality of AIDS-related cryptococcal meningitis}

Currently, cryptococcal meningitis represents the main cause of HIV-related opportunistic meningitis in Brazil (OLIVEIRA et al., 2006; VIDAL et al., 2008; LEIMANN \& KOIFMAN, 2009), and in most low and middle-income countries (HARRISON, 2009). Mortality continues to be unacceptable high. In retrospective and prospective hospital-based studies performed in Brazil and Argentina, the case fatality rates have ranged from $26 \%$ to $63 \%$ (METTA et al., 2002; PASQUALOTTO et al., 2004; MOREIRA et al., 2006; MÓNACO \& TAMAYO ANTABAK, 2008; LINDENBERG et al., 2008; VIDAL et al., 2012). This figure is similar to $24-50 \%$ reported in interventional studies carried out in Africa and Asia (BICANIC et al., 2007; BICANIC et al., 2009; JARVIS et al., 2009; JARVIS et al., 2014). In contrast, mortality ranges from $2.5 \%$ to $25 \%$ in high resource countries (KAPLAN et al., 2000; DROMER et al., 2004; D'ARMINIO MONFORTE et al., 2004; DILLEY et al., 2005; LORTHOLARY et al., 2006; DROMER et al., 2007; ANTINORI et al., 2008). Thus, improved outcomes are possible.

\section{Mortality in high-income versus low and middle-income countries}

The differences in outcome between low and middle-income countries versus high-income countries have several potential explanations. First, late testers and late presenters with HIV infection are more frequent in low and middle-income countries (GRECO \& SIMÃO, 2007). Low CD4 count at ART initiation and more advanced disease constitutes strong predictors of mortality in the first year of ART (TUBOI et al., 2009). Second, cryptococcal meningitis usually reveals HIV-infection in lowand middle-income countries but some studies showed other alternative scenario, particularly in middle-income countries: most cryptococcal meningitis are aware of their HIV-status prior to admission (with or without prior ART use) (VIDAL et al., 2012; MORA et al., 2012). This finding suggests continued missed opportunities to initiate or maintain ART with persistent barriers to adherence and retention-in-care of a subset of patients. With expanded ART access, virologic failure and AIDS-progression is beginning to become more frequent. Third, severe immunosuppression (also frequent in high-income countries) but particularly concomitant anemia, malnutrition, and severe cryptococcal meningitis are common in low and middle-income countries (VIDAL et al., 2012). The delay in presentation with diagnosis only when cryptococcal meningitis is advanced is common (VIDAL et al., 2012; WHO, 2011). This is evident by the increased proportions of patients presenting with neurologic complications in resource-limited setting (KAMBUGU et al., 2008; SCARBOROUGH et al., 2007). Fourth, rapid diagnosis is paramount to optimizing survival; however, diagnosis is difficult when optimum laboratory support is unavailable in most low and middle-income countries. CSF microscopy with India ink staining is most commonly used but misses $15-20 \%$ of the low burden infections which are easiest to treat (BOULWARE et al. 2014). Although larger urban centers have a reasonable laboratory infrastructure, the availability of a timely diagnosis is highly variable by country and within country.
Fifth, optimal medical management is not available frequently in low and middle-income countries. Combination antifungal induction therapy and utilization of adequate measures to control of intracranial pressure are heterogeneous in routine practice.

\section{Prognostic factors associated with mortality}

Several risk factors for treatment failure or mortality have been reported elsewhere for AIDS-associated cryptococcal meningitis (DROMER et al., 2007; CHARLIER et al., 2008; BICANIC et al., 2009; JARVIS et al., 2014; VIDAL et al., 2012). The major risk factors for mortality include: fungal burden (i.e. assessable by quantitative microscopy, quantitative cultures, and/or cryptococcal antigen titers), rate of fungal clearance, altered mental status, paucity of CSF WBC pleocytosis, abnormal brain imaging, elevated intracranial pressure at admission (which is uncontrolled), lack of therapeutic lumbar punctures to control pressure, disseminated infection, and duration of antecedent symptoms.

\section{Strategies to reduce mortality and morbidity due to AIDS-related cryptococcal meningitis}

A number of strategies to reduce mortality and morbidity due to cryptococcal meningitis were reviewed elsewhere (VIDAL et al., 2013). Table 1 depicts some key potential strategies to reduce the effects of AIDS-related cryptococcal meningitis.

\section{Table 1}

Potential key points to reduce mortality and morbidity due to AIDS-related cryptococcal meningitis

1. Earlier HIV diagnosis and ART initiation with retention-in-care, prior to AIDS.

2. ART adherence and retention-in-care.

3. Pre-ART CrAg screening using lateral flow assay or latex agglutination.

a. Pre-ART positive $\mathrm{CrAg}$ predicts future cryptococcal meningitis despite ART.

b. Preemptive treatment with fluconazole $400 \mathrm{mg}$ twice daily for 2 weeks, then $400 \mathrm{mg}$ daily for 8 weeks, and then $200 \mathrm{mg} /$ day until CD4 > 200 is recommended.

c. Primary prophylaxis is less cost-effective than $\mathrm{CrAg}$ screen and treat approach.

4. Improved cryptococcal meningitis care using lateral flow assay or latex agglutination.

5. Improved cryptococcal meningitis care.

a. Induction therapy with amphotericin B $(1.0 \mathrm{mg} / \mathrm{kg} /$ day $)$ plus flucytosine $100 \mathrm{mg} / \mathrm{kg} /$ day (in four doses). When flucytosine is not available, fluconazole $800-1200 \mathrm{mg}$ /day (in two doses) is the alternative.

b. Preemptive IV fluid and electrolyte $\left(\mathrm{K}^{+}, \mathrm{Mg}^{++}\right)$supplementation during amphotericin administration to decrease toxicity.

c. Aggressive control of elevated intracranial pressure with therapeutic lumbar punctures.

d. Quantitative microscopy can predict culture status and guide when to switch to consolidation therapy. 


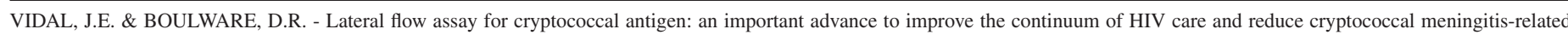
mortality. Rev. Inst. Med. Trop. Sao Paulo, 57(Suppl 19): 38-45, 2015.

\section{Lateral flow assay}

\section{Which the classical diagnosis of cryptococcal meningitis?}

The diagnosis of cryptococcosis is relatively simple with several potential techniques: direct visualization, histopathology, culture, and detection of CrAg in bodily fluids (PERFECT \& BICANIC, 2014). Direct visualization using India ink staining has been the traditional method for identifying Cryptococcus organisms, particularly in resource-limited settings. The sensitivity is $\sim 80-85 \%$ in AIDS-related cryptococcal meningitis but can be highly variable and often operator dependent, as lysed leukocytes can be mistaken for fungal elements (MAKADZANGE \& McHUGH, 2014). The Giemsa stain and Hematoxylin and Eosin are not very useful for the histopathological diagnosis of cryptococcosis. The histopathology of infected tissue with specific stains shows the cryptococcal capsule (mucicarmine and Alcian blue stains), presence of melanin (Fontana-Manson), or grocott's methenamine silver stain of the fungal cell wall (PERFECT \& BICANIC, 2014). Cryptococcus can readily be cultured from most sites, using routine and automated systems. In AIDS-related cryptococcal meningitis, the sensitivity of CSF and blood cultures are $\sim 90 \%$ and $\sim 50-70 \%$, respectively (ANTINORI, 2013). Interesting, culture sensitivity is dependent on CSF volume ( 82\% for $10 \mu \mathrm{L}, 94 \%$ for $100 \mu \mathrm{L}$ ) (BOULWARE et al., 2014). Detection of CrAg, a component of the organism's glucoronoxylomannan polysaccharide capsule, is the most sensitive diagnostic tool for cryptococcosis (MAKADZANGE \& McHUGH, 2014; PERFECT \& BICANIC, 2014). Detection of CrAg in serum and CSF by latex agglutination test (CrAg-latex) or enzyme immunoassays (EIA) has been available for over 35 years (PERFECT \& BICANIC, 2014). Most comparative studies used cultures as gold standard. CrAg-latex serum sensitivity ranged from $83-97 \%$. The tests with the lower sensitivity did not use pronase on serum specimens. The CrAg-latex specificity on serum ranged from 93 to $100 \%$. The CSF sensitivity of the CrAg-latex test was high ranging from 93 to $100 \%$ with specificity ranging from $93-98 \%$. The sensitivity and specificity of the EIA on serum were $94 \%$ and $96 \%$, respectively. The sensitivity and specificity on EIA testing of CSF were $100 \%$ and $98 \%$, respectively. Among persons with AIDS with meningitis, CrAg should be always evaluated, including when India ink fails to identify yeast. For example, in Uganda, the most common cause of meningitis among HIV-infected persons with a negative India ink is still Cryptococcus (BOULWARE et al., 2014). Although the CrAg-latex performs well when compared with EIA and culture, its main limitation is that latex is a cumbersome manual test with subjectivity in the interpretation of the result. CrAg-latex and EIA also requires laboratory equipment and refrigeration of reagents, making it unsuitable for use in settings with no or minimal infrastructure (MAKADZANGE \& McHUGH, 2014). The need for refrigeration dramatically raises the cost of the test in resource-limited settings. CrAg-latex has reduced sensitivity for $\mathrm{CrAg}$ of serotype $\mathrm{C}$ (i.e. C. gattii), and EIA shows reduced sensitivity for $\mathrm{CrAg}$ of serotype $\mathrm{C}$ and $\mathrm{D}$. False positives rate is less than $1 \%$ and generally is explained by technical issues or other infections or contamination (i.e Trichosporon beigelii, Capnocytophaga canimorsus, and Stomatococcus mucilaginosus). False negative results can occasionally be observed with early infections when there is low fungal burden, with prozone phenomenon, and with poorly encapsulated organisms (ANTINORI, 2013; PERFECT \& BICANIC, 2014). Table 2 shows a comparison of CrAg LFA with other immunoassays.
Table 2

Comparison of lateral flow assay with other immunoassays*

Lateral flow assay: requires no pretreatment of sample; high sensitivity for $\mathrm{CrAg}$ of all serotypes; suitable for use in settings with no, minimal or advanced infrastructure; rapid results (10 minutes); low overall cost.

Latex agglutination: serum samples pretreated with pronase; reduced sensitivity for $\mathrm{CrAg}$ of serotype $\mathrm{C}$; not suitable for use in settings with no or minimal infrastructure; rapid results (10-30 minutes, depending on specimen type); intermediate overall cost.

Enzyme immunoassay: requires no pretreatment of sample; reduced sensitivity for $\mathrm{CrAg}$ of serotypes $\mathrm{C}$ and $\mathrm{D}$; not suitable for use in settings with no or minimal infrastructure; longer time to result (35-45 minutes); higher overall cost.

*Adapted from KOZEL \& BAUMAN, 2012.

\section{How does the cryptococcal antigen lateral flow assay works?}

The CrAg LFA (Immuno-Mycologics, Norman, OK, USA) is a lateral flow immunochromatographic assay and was designed to meet two critical criteria for diagnosis: 1) the test is able to detect $\mathrm{CrAg}$ of all Cryptococcus serotypes, and 2) the test can be used in settings with minimal or no infrastructure (KOZEL \& BAUMAN, 2012). The CrAg LFA addresses the needs of low-income countries and meets the World Health Organization (WHO) ASSURED criteria for diagnostic tests

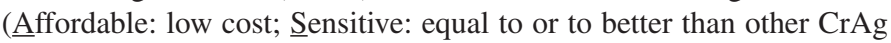

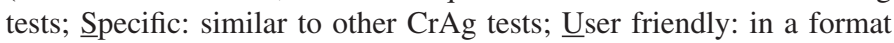
similar to the pregnancy test strip; Rapid/robust: produces a clear result in 10 minutes; Equipment-free: the test requires no electricity or laboratory infrastructure; and Delivered: the test is small, lightweight, requires no refrigeration and has a long shelf life).

The CrAg LFA uses monoclonal antibodies which allows for consistent reagent quality and performance. The LFA uses a combination of two monoclonals. One monoclonal antibody is highly reactive with $\mathrm{CrAg}$ of serotypes $\mathrm{A}, \mathrm{B}$, and $\mathrm{C}$; the second monoclonal is highly reactive with CrAg of serotypes A and D. Used together, the antibodies are highly reactive with $\mathrm{CrAg}$ across the range of cryptococcal serotypes, an advantage when compared with CrAg-latex or EIA.

Figure 1 shows the mechanism of CrAg LFA. The LFA uses gold-conjugated, two monoclonal antibodies impregnated onto an immunochromatographic test strip. If cryptococcal antigen is present in a specimen, suspended, gold-conjugated antibodies bind to the antigen. The gold-antibody-CrAg complex migrates by capillary action up the test trip, interacts with immobilized monoclonal antibodies against $\mathrm{CrAg}$, and forms a red line. The Immy CrAg LFA kit contains $50 \mathrm{CrAg}$ LFA test strips, specimen diluent, titration diluent, and positive control. The kit can be stored at room temperature for $\sim 2$ years.

The CrAg LFA provides both qualitative and semi-quantitative, e.g. titer, results. The test requires five simple steps shown in the Figure 2. The presence of two lines (test and control lines), regardless of the intensity of the test line indicates a positive result. A single control line indicates a negative test result. If the control line does not appear, the 


\section{A}

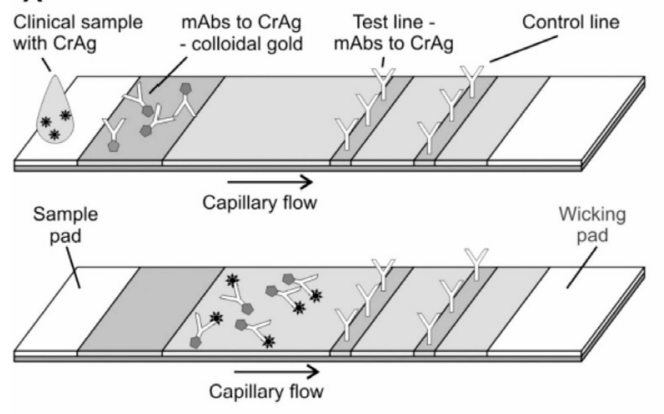

B

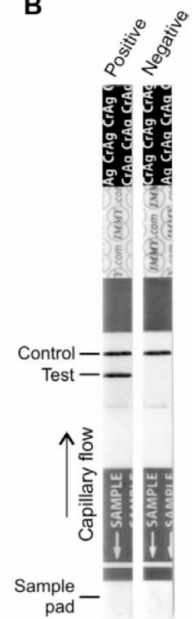

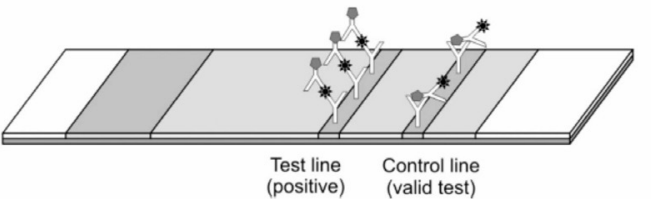

al., 2012). CrAg LFA is approximately 5-fold more sensitive than CrAglatex when directly comparing semi-quantitative titers by serial dilution (BOULWARE et al., 2014). For example, a specimen positive at 1:8 $\mathrm{CrAg}$ titer by CrAg-latex is generally positive at 1:40 titer dilution by LFA. There is individual variation, however. In routine clinical conditions usually titration is not possible due to costs, thus, a qualitative result is enough to implement this strategy. Laboratories may consider running two dilutions at $1: 160$ and 1:1280 to perform titers to help risk stratify into low $(<1: 160)$, medium $(\geq 1: 160)$, high burden $(\geq 1: 1280)$ of infection. The use of routine serum or plasma antigenemia screening in ART-naïve adults with CD $4<100$ cells/ $\mu \mathrm{L}$, followed by preemptive fluconazole therapy can reduce the development of cryptococcal meningitis and improve survival. The WHO recommended preemptive treatment for subclinical positive $\mathrm{CrAg}$ is fluconazole $400 \mathrm{mg}$ twice daily for two weeks followed by 400 mg daily for eight weeks (WHO, 2011). This WHO recommendation works best for persons with low burden of infection (CrAg titer < 1:160). The necessity of secondary prophylaxis is unclear, but for higher burdens of infection (i.e. CrAg titers > 1:160), fluconazole $200 \mathrm{mg} /$ day until CD4 $>200$ cells $/ \mu \mathrm{L}$ is advisable. This screening and treatment strategy is highly cost-effective, and is WHO recommended among HIV-infected adults not receiving effective ART where the prevalence of cryptococcal antigenemia is $\geq 3 \%$ (WHO, 2011). This is generally anyone with CD4 $<100$ cells $/ \mu \mathrm{L}$ worldwide; however what is the optimal threshold (i.e. $100,125,150,200$ cells $/ \mu \mathrm{L}$ ) for cost-benefit of screening is not known.

Currently, the Brazilian Cryptococcosis Network is performing a multicenter study using CrAg LFA in order to determine the $\mathrm{CrAg}$ prevalence among persons living with AIDS. In the meanwhile, seems reasonable to incorporate in clinical practice the screening and preemptive treatment for subclinical cryptococcosis strategy; however, $\mathrm{CrAg}$ screening implementation presents individual and public health challenges (MFINANGA et al., 2015; GOVENDER et al., 2015). CrAg testing is recommended for pre-ART screening (WHO, 2011), and the CrAg LFA has several advantages over CrAg-latex or EIA for actual implementation of a screening program.

Some authors recommend that in centers where lumbar puncture is readily available, this procedure should be offered to all $\mathrm{CrAg}+$ patients, but if it is not logistically feasible this should not be a barrier to the implementation screening (JARVIS et al., 2012). The role of lumbar puncture in asymptomatic $\mathrm{CrAg}+$ patients is yet to be defined. Symptoms are not reliable for detection of dissemination to the central nervous system development of cryptococcal meningitis, particularly when the CrAg titer is $\geq 1: 8$ (JARVIS et al., 2009; MEYA et al., 2010; RAJASINGHAM et detectable serum cryptococcal antigenemia between 2-21\% in patients with CD4 < 100 cells/ $\mu \mathrm{L}$ entering into HIV care (MEYA et al., 2010). Most studies about CrAg screening were performed with CrAg-latex testing. An isolated positive serum CrAg before ART predicts the

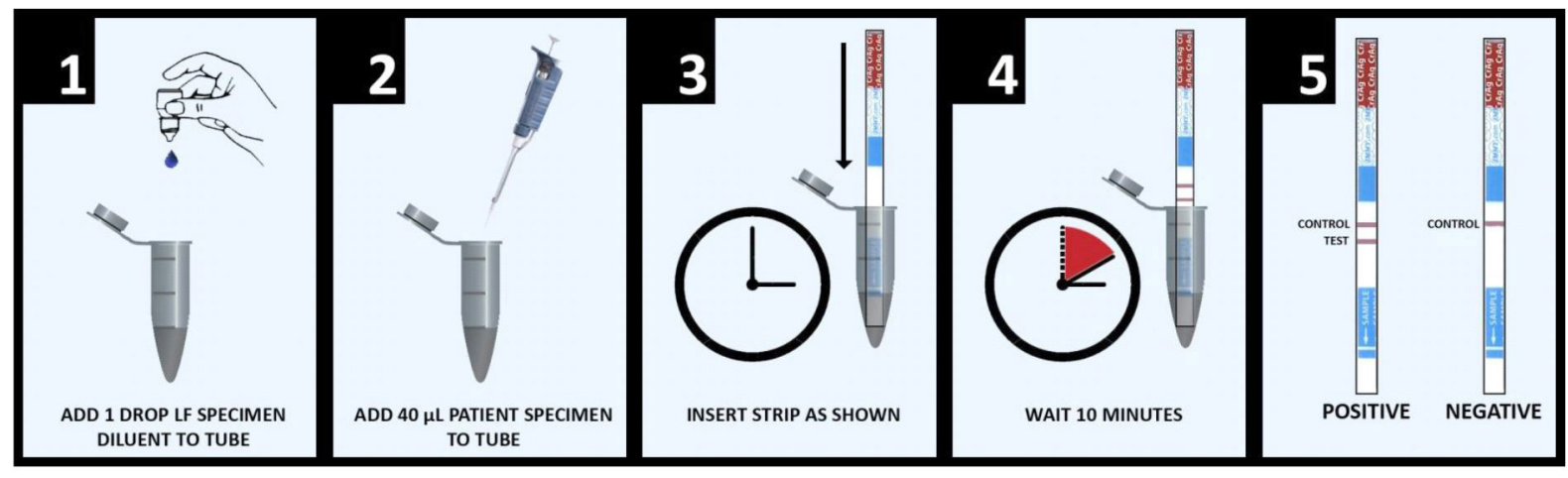

Fig. 2 - Five easy steps to perform the detection of cryptococcal antigen using lateral flow assay. Step 1: add one drop of specimen to a tube. Step 2: add of $40 \mu \mathrm{L}$ (1 drop) of patient specimen to the tube. Step 3: insert the LFA strip into the tube. Step 4: incubate for 10 minutes. Step 5: interpret results. (From PELFREY \& BAUMAN, 2012). 
VIDAL, J.E. \& BOULWARE, D.R. - Lateral flow assay for cryptococcal antigen: an important advance to improve the continuum of HIV care and reduce cryptococcal meningitis-related mortality. Rev. Inst. Med. Trop. Sao Paulo, 57(Suppl 19): 38-45, 2015.

(WILLIAMS et al., 2015). Asymptomatic persons may have CSF positivity, and symptomatic persons may have CSF abnormalities but no diagnostic evidence of Cryptococcus. CrAg titer in blood can be quite helpful to risk stratify. In persons with low CrAg titers $(<1: 160)$, they can be treated safely without lumbar punctures (unpublished data). Persons with high CrAg titers ( $\geq 1: 1280$ ) should be assumed to have disseminated disease, regardless of symptoms. The role of lumbar punctures to exclude active CNS cryptococcal disease has substantial variations in opinion. Excluding increased intracranial pressure in a symptomatic person is as important as to whether the CSF has detectable CrAg. We propose an algorithm for implementation of CrAg screening considering CrAg titres (Fig. 3).

\section{Diagnosis of cryptococcal meningitis}

Data from manufacturers indicate that LFA sensitivity, specificity, positive predictive value, and negative predictive value are $99.5 \%, 99 \%$, $98 \%$, and $99.7 \%$, respectively, using serum, plasma, CSF or urine, when compared to culture (Table 3). Some studies validated LFA versus LA and EIA in both plasma and CSF samples in laboratory settings showing high values of concordance (JARVIS et al., 2011; LINDSLEY et al., 2011; BINNICKER et al., 2012; McMULLAN et al., 2012). A multi-site study prospectively validated LFA in patients with suspected meningitis in sub-Saharan Africa (BOULWARE et al., 2014). In this comparative study, LFA had the best performance (sensitivity $99.3 \%$, specificity 99.1\%) while CrAg-latex sensitivity (97-97.8\%) and specificity (85.9-100\%) varied between manufacturers. Interesting, CrAg LFA was the only CSF positive test in $1.5 \%$ of cases, which also had peripheral blood $\mathrm{CrAg}$ positivity.

CrAg LFA has been evaluated with paired specimens from patients with cryptococcal disease (Table 4). As expected, since the presence of $\mathrm{CrAg}$ is dependent on disease progression, $\mathrm{CrAg}$ was found in serum but not CSF of some patients, indicating non-meningeal cryptococcal disease. It was also found that $\mathrm{CrAg}$ concentrations in urine are lower than in serum, plasma, or CSF, as seen by urine LFA-negative results when serum, plasma, and CSF are positive. Urine LFA can have false positives, thus any positive result should always be confirmed in blood.

Diagnosis of cryptococcosis using urine or whole blood specimens is a true point-of-care test, accessible in any setting without laboratory. Urine or whole blood are still undergoing evaluation and are not yet FDA-approved. Available data about urine shows high sensitivity and specificity (JARVIS et al, 2011; PELFREY \& BAUMAN, 2012). A recent study that reported $100 \%$ agreement between whole blood, serum and plasma LFA results demonstrated that fingerstick CrAg is a reliable bedside diagnostic test (WILLIAMS et al., 2015). Fingerstick LFA seems

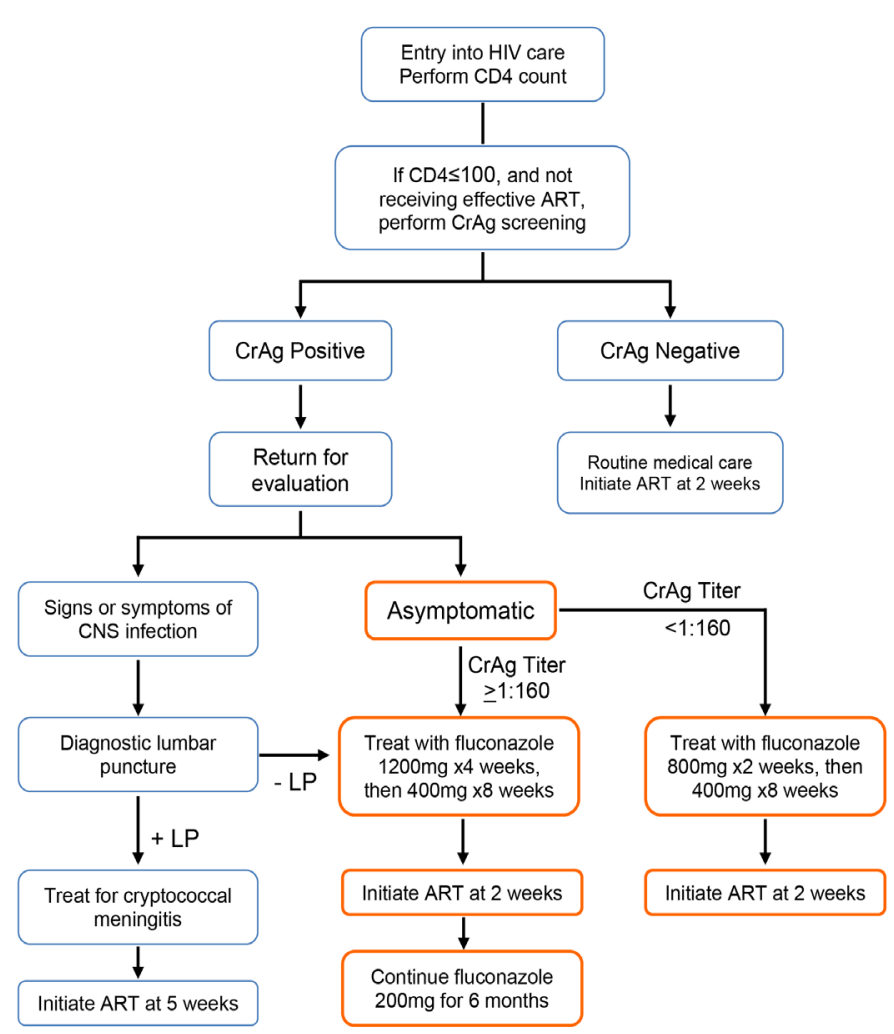

Fig. 3 - A proposal of an algorithm for clinical implementation of cryptococcal antigen screening and targeted preemptive therapy for the prevention of cryptococcal meningitis.

to be an important and simple tool for the diagnosis of cryptococcal meningitis. An instruction video on fingerstick LFA testing is available at: youtu.be/0RwN3p7XirQ

\section{CrAg Lateral flow assay titres}

High fungal burden and slow clearance of infection on treatment, together with altered mental status, are the most important drivers of acute cryptococcal-related mortality (JARVIS et al., 2014). High fungal burden can be estimated with a baseline high titer of CrAg in serum or CSF (i.e CrAg-latex > 1:1024). In this line, baseline LFA titers correlate with quantitative cultures and predict 2- and 10-week mortality (KABANDA et al, 2014). Although CrAg titers generally decline gradually over the time at variable rates, older studies report that CSF, serum or plasma

Table 3

Sensitivity, specificity, positive predictive value, and negative predictive value of the lateral flow assay compared to cryptococcal culture*

\begin{tabular}{|c|c|c|c|c|c|c|c|c|c|}
\hline $\begin{array}{l}\text { Specimen } \\
\text { Type }\end{array}$ & $\mathrm{n}$ & Sensitivity & $95 \% \mathrm{CI}$ & Specificity & $95 \% \mathrm{CI}$ & PPV & $95 \% \mathrm{CI}$ & NPV & $95 \% \mathrm{CI}$ \\
\hline Serum & 693 & $100 \%$ & $98-100 \%$ & $99 \%$ & $97-99 \%$ & $97 \%$ & $94-99 \%$ & $100 \%$ & $99-100 \%$ \\
\hline Plasma & 135 & $100 \%$ & $96-100 \%$ & $100 \%$ & $93-100 \%$ & $100 \%$ & $96-100 \%$ & $100 \%$ & $97-100 \%$ \\
\hline CSF & 261 & $100 \%$ & $97-100 \%$ & $97 \%$ & $92-99 \%$ & $97 \%$ & $93-99 \%$ & $100 \%$ & $97-100 \%$ \\
\hline Urine & 674 & $98.4 \%$ & $95-99.5 \%$ & $99 \%$ & $98-99.8 \%$ & $97 \%$ & $95-99.7 \%$ & $99 \%$ & $98-99.9 \%$ \\
\hline Total & 1763 & $99.5 \%$ & $98-99.8 \%$ & $99 \%$ & $98.0-99 \%$ & $97 \%$ & $96-99 \%$ & $99.7 \%$ & $99.2-99.9 \%$ \\
\hline
\end{tabular}

*From PELFREY \& BAUMAN, 2012. 


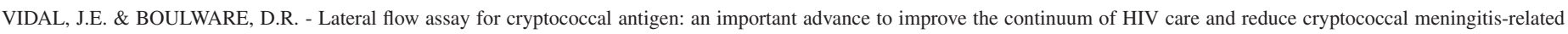
mortality. Rev. Inst. Med. Trop. Sao Paulo, 57(Suppl 19): 38-45, 2015.

Table 4

Lateral flow assay paired specimen comparisons from persons with cryptococcal disease*

\begin{tabular}{|c|c|c|c|c|c|}
\hline Comparison & $\mathrm{n}$ & $\%$ Agreement Positive & $95 \% \mathrm{CI}$ & $\%$ Agreement Negative & $95 \% \mathrm{CI}$ \\
\hline Serum vs. Urine & 169 & $97.8 \%$ & $94-99 \%$ & $100 \%$ & $89-100 \%$ \\
\hline Serum vs. Plasma & 83 & $100 \%$ & $95-100 \%$ & $100 \%$ & $34-100 \%$ \\
\hline Serum vs. CSF & 118 & $93.7 \%$ & $89-97 \%$ & $100 \%$ & $91-100 \%$ \\
\hline Plasma vs. Urine & 81 & $98.8 \%$ & $93-100 \%$ & N/A & NB/A \\
\hline CSF vs. Urine & 104 & $98.5 \%$ & $92-100 \%$ & $91.7 \%$ & $78-97 \%$ \\
\hline CSF vs. Plasma & 18 & $100 \%$ & $82-100 \%$ & N/A & N/A \\
\hline
\end{tabular}

*From PELFREY \& BAUMAN, 2012.

CrAg may remain positive for months to years, and CrAg titres are not recommended to be routinely measured to monitor response to treatment (POWDERLY et al., 1994). LFA presents similar limitation (KABANDA et al., 2014). CrAg tests and India ink are not useful for diagnosis of subsequent episodes of cryptococcal meningitis due to the possibility of long-term positivity (GOVENDER et al., 2013). Thus, a positive CSF culture for $C$. neoformans is the only one test to confirm mycological relapse or treatment failure (MUSUBIRE et al. 2013).

\section{CrAg Lateral flow assay and Cryptococcus gattii disease}

As mentioned above, the LFA uses two monoclonal antibodies impregnated onto an immunochromatographic test strip to detect $\mathrm{CrAg}$ for all four Cryptococcus serotypes which is an advantage in comparison with CrAg-latex or EIA (KOZEL \& BAUMAM, 2012). Nevertheless, experience using the LFA to diagnose $C$. gattii disease is limited but it is likely to perform similarly as in $C$. neoformans disease. Further evaluation of its utility in the diagnosis of $C$. gattii diseases is needed, particularly in patients with extra-CNS or lung diseases (CHEN et al., 2014).

\section{CONCLUSIONS}

Despite relevant improvements during the ART-era, AIDS-related cryptococcal meningitis remains frequent and causes an unacceptable high mortality, particularly in low and middle-income countries. LFA allows a simple, rapid and low cost test for the diagnosis of cryptococcosis and is recommended for use with serum, plasma or CSF in symptomatic patients. In addition, CrAg LFA screening using plasma or serum has the potential to identify patients with asymptomatic infection who should receive pre-emptive fluconazole. Available data suggest that whole blood seems to be useful in these two scenarios. Thus, a fingerstick CrAg LFA represent a true point-of-care test to prevention and diagnosis of AIDSrelated cryptococcosis.

\section{RESUMO}

Ensaio de Fluxo Lateral para antígeno criptocócico: um importante avanço para melhorar o continuum de cuidados com HIV e reduzir a mortalidade relacionada à meningite criptocóccica

A meningite criptocócica continua causando um substancial índice de óbitos em pacientes infectados por HIV em países de baixa e média renda. Ferramentas diagnósticas para detecção do antígeno capsular polissacarídico criptocócico $(\mathrm{CrAg})$ em soro e líquor tais como o teste de aglutinação de látex (latex-CrAg) ou o imunoensaio (EIE) têm sido utilizadas por muitos anos. Técnicas diagnósticas mais aprimoradas seriam cruciais nas fases assintomática e sintomática da criptococose para reduzir a mortalidade. Recentemente, o ensaio de fluxo lateral para detecção do antígeno criptocócico (LFA CrAg) foi incluído no arsenal diagnóstico. Contrariamente aos outros testes, LFA CrAg é um ensaio imunocromatográfico em formato similar ao teste de gravidez, e requer pouca ou nenhuma infraestrutura laboratorial. Este teste preenche os critérios ASSURED (Affordable, Sensitive, Specific, User friendly, Rapid/ robust, Equipment-free, Delivered) da Organização Mundial da Saúde e pode ser utilizado em soro, plasma, sangue total ou líquor para o diagnóstico da criptococose. LFA CrAg tem melhor sensibilidade analítica para o C. gattii que o teste de látex-CrAg ou EIE. A prevenção da doença criptocócica constituiria uma nova aplicação do LFA CrAg, mediante a triagem de amostras de sangue para a identificação de infecção sub-clínica em pacientes infectados pelo HIV que não apresentam sintomas, possuem contagem de $\mathrm{CD} 4<100$ células/ $\mu \mathrm{L}$ e não recebem terapia antirretroviral eficaz. A triagem de $\mathrm{CrgA}$ em amostras de plasma remanescente da contagem de CD4 pode identificar pacientes com infecção assintomática que precisam urgentemente de tratamento preemptivo com fluconazol, evitando assim a progressão para doença sintomática e/ou óbito.

\section{CONFLICT OF INTEREST}

Potential conflict of interest: the authors have not any link with the manufacturers and distributors of the laboratory tests mentioned in this paper.

\section{REFERENCES}

1. Antinori S, Ridolfo AL, Fasan M, Magni C, Galimberti L, Milazzo L, et al. AIDSassociated cryptoccocosis: a comparison of epidemiology, clinical features and outcome in the pre- and post-HAART eras. Experience of a single centre in Italy. HIV Med. 2008;10:6-11.

2. Antinori S. New insights into HIV/AIDS-associated cryptococcosis. ISRN AIDS 2013;2013:471363.

3. Bicanic T, Meintjes G, Wood R, Hayes M, Rebe K, Bekker LG, et al. Fungal burden, early fungicidal activity, and outcome in cryptococcal meningitis in antiretroviral naïve or antiretroviral-experienced patients treated with amphotericin B or fluconazole. Clin Infect Dis. 2007;45:76-80.

4. Bicanic T, Muzoora C, Brouwer AE, Meintjes G, Longley N, Taseera K, et al. Independent association between rate of clearance of infection and clinical outcome of HIV-associated cryptococcal meningitis: analysis of a combined cohort of 262 patients. Clin Infect Dis. 2009;49:702-9. 
VIDAL, J.E. \& BOULWARE, D.R. - Lateral flow assay for cryptococcal antigen: an important advance to improve the continuum of HIV care and reduce cryptococcal meningitis-related mortality. Rev. Inst. Med. Trop. Sao Paulo, 57(Suppl 19): 38-45, 2015.

5. Binnicker MJ, Jespersen DJ, Bestrom JE, Rollins LO. Comparison of four assays for the detection of cryptococcal antigen. Clin Vaccine Immunol. 2012;19:1988-90.

6. Boulware DR, Rolfes MA, Rajasingham R, von Hohenberg M, Qin Z, Taseera K, et al. Multisite validation of cryptococcal antigen lateral flow assay and quantification by laser thermal contrast. Emerg Infect Dis. 2014;20:45-53.

7. Charlier C, Dromer F, Lévêque C, Chartier L, Cordoliani YS, Fontanet A, et al. Cryptococcal neuroradiological lesions correlate with severity during cryptococcal meningoencephalitis in HIV-positive patients in the HAART era. PLOS ONE. 2008;3:e1950.

8. Chen SC, Meyer W, Sorrell TC. Cryptococcus gattii infections. Clin Microbiol Rev. 2014;27:981-1023.

9. d'Arminio Monforte A, Cinque P, Mocroft A, Goebel FD, Antunes F, Katlama C, et al. Changing incidence of central nervous system diseases in the EuroSIDA cohort. Ann Neurol. 2004;55:320-8.

10. Dilley JW, Schwarcz S, Loeb L, Hsu L, Nelson K, Scheer S. The decline of incident cases of HIV-associated neurological disorders in San Francisco, 1991-2003. AIDS. $2005 ; 19: 634-5$

11. Dromer F, Mathoulin-Pélissier S, Fontanet A, Ronin O, Dupont B, Lortholary O, et al. Epidemiology of HIV-associated cryptococcosis in France (1985-2001): comparison of the pre- and post-HAART eras. AIDS. 2004;18:555-62.

12. Dromer F, Mathoulin-Pelissier S, Launay O, Lortholary O, French Cryptococcosis Study Group. Determinants of disease presentation and outcome during cryptococcosis: the Crypto A/D Study. PLOS Med. 2007;4:297-308.

13. Govender NP, Meintjes G, Bicanic T, Dawood H, Harrison TS, Jarvis JN, et al. Guideline for the prevention, diagnosis and management of cryptococcal meningitis among HIV-infected persons: 2013 update. S Afr HIV Med. 2013;14:76-86.

14. Govender NP, Roy M, Mendes JF, Zulu TG, Chiller TM, Karstaedt AS. Evaluation of screening and treatment of cryptococcal antigenaemia among HIV-infected persons in Soweto, South Africa. HIV Med. 2015;16:468-76. doi: 10.1111/hiv.12245

15. Greco DB, Simão M. Brazilian policy of universal access to AIDS treatment: sustainability challenges and perspectives. AIDS. 2007;21(Suppl 4):37-45.

16. Guimarães MD. Estudo temporal das doenças associadas à AIDS no Brasil, 19801999. Cad Saude Publica. 2000;16(Suppl 1):S21-S36.

17. Harrison TS. The burden of HIV-associated cryptococcal disease. AIDS. 2009;23:5312 .

18. Jarvis JN, Harrison TS. HIV-associated cryptococcal meningitis. AIDS. 2007;21:211929.

19. Jarvis JN, Boulle A, Loyse A, Bicanic T, Rebe K, Williams A, et al. High ongoing burden of cryptococcal disease in Africa despite antiretroviral roll out. AIDS. 2009;23:1182-3.

20. Jarvis JN, Meintjes G, Williams A, Brown Y, Crede T, Harrison TS. Adult meningitis in a setting of high HIV and TB prevalence: findings from 4961 suspected cases. BMC Infect Dis. 2010;10:67.

21. Jarvis JN, Percival A, Bauman S, Pelfrey J, Meintjes G, Williams GN, et al. Evaluation of a novel point-of-care cryptococcal antigen test on serum, plasma, and urine from patients with HIV-associated cryptococcal meningitis. Clin Infect Dis. 2011;53:101923.

22. Jarvis JN, Govender N, Chiller T, Park BJ, Longley N, Meintjes G, et al. Cryptococcal antigen screening and preemptive therapy in patients initiating antiretroviral therapy in resource-limited settings: a proposed algorithm for clinical implementation. J Int Assoc Physicians AIDS Care (Chic). 2012;11:374-9.
23. Jarvis JN, Bicanic T, Loyse A, Namarika D, Jackson A, Nussbaum JC, et al Determinants of mortality in a combined cohort of 501 patients with HIV-associated cryptococcal meningitis: implications for improving outcomes. Clin Infect Dis. 2014;58:736-45

24. Kabanda T, Siedner MJ, Klausner JD, Muzoora C, Boulware DR. Point-of-care diagnosis and prognostication of cryptococcal meningitis with the cryptococcal antigen lateral flow assay on cerebrospinal fluid. Clin Infect Dis. 2014;58:113-6.

25. Kambugu A, Meya DB, Rhein J, O'Brien M, Janoff EN, Ronald AR, et al. Outcomes of cryptococcal meningitis in Uganda before and after the availability of highly active antiretroviral therapy. Clin Infect Dis. 2008;46:1694-701.

26. Kaplan JE, Hanson D, Dworkin MS, Frederick T, Bertolli J, Lindegren ML, et al Epidemiology of human immunodeficiency virus-associated opportunistic infections in the United States in the era of highly active antiretroviral therapy. Clin Infect Dis 2000;30(Suppl 1):5-14

27. Kozel TR, Bauman SK. CrAg Lateral Flow Assay for Cryptococcosis. Expert Opin Med Diagn 2012;6:245-51.

28. Leimann BCQ, Koifman RJ. Official information systems for cryptococcal meningitis, state of Rio de Janeiro, Southeastern Brazil. Rev Saúde Pública 2009;43:1-4.

29. Lindenberg A de S, Chang MR, Paniago AM, Lazéra M dos S, Moncada PM, Bonfim GF, et al. Clinical and epidemiological features of 123 cases of cryptococcosis in Mato Grosso do Sul, Brazil. Rev Inst Med Trop Sao Paulo. 2008;50:75-8.

30. Lindsley MD, Mekha N, Baggett HC, Surinthong Y, Autthateinchai R, Sawatwong $\mathrm{P}$, et al. Evaluation of newly developed lateral flow immunoassay for the diagnosis of cryptococcosis. Clin Infect Dis. 2011;53:321-5.

31. Litvintseva AP, Xu J, Mitchell TG. Population structure and ecology of Cryptococcus neoformans and Cryptococcus gattii. In: Heitman J, Kozel TR, Kwon-Chung KJ, Perfect JR, Casadevall A, editors. Cryptococcus: from human pathogen to model yeast. Washington: ASM Press; 2011. p. 97-112.

32. Lortholary O, Poizat G, Zeller V, Neuville S, Boibieux A, Alvarez M, et al. Long-term outcome of AIDS-associated cryptococcosis in the era of combination antiretroviral therapy. AIDS. 2006;20:2183-91.

33. Makadzange AT, McHugh G. New approaches to the diagnosis and treatment of cryptococcal meningitis. Semin Neurol. 2014;34:47-60.

34. McMullan BJ, Halliday C, Sorrell TC, Judd D, Sleiman S, Marriott D, et al. Clinical utility of the cryptococcal antigen lateral flow assay in a diagnostic mycology laboratory. PLOS ONE. 2012;7:e49541.

35. Metta HA, Corti ME, Negroni R, Helou S, Arechavala A, Soto I, et al. Disseminated cryptococcosis in patients with AIDS. Clinical, microbiological, and immunologoical analysis of 51 patients. Rev Argent Microbiol. 2002;34:117-23.

36. Meya DB, Manabe YC, Castelnuovo B, Cook BA, Elbireer AM, Kambugu A, et al. Cost-effectiveness of serum cryptococcal antigen screening to prevent deaths among HIV-infected persons with a CD4+ cell count $<$ or $=100$ cells $/$ microL who start HIV therapy in resource-limited settings. Clin Infect Dis. 2010;51:448-55.

37. Mfinanga S, Chanda D, Kivuyo SL, Guinness L, Bottomley C, Simms V, et al Cryptococcal meningitis screening and community-based early adherence support in people with advanced HIV infection starting antiretroviral therapy in Tanzania and Zambia: an open-label, randomised controlled trial. Lancet. 2015;385(9983):2173-82.

38. Mirza SA, Phelan M, Rimland D, Graviss E, Hamill R, Brandt ME, et al. The changing epidemiology of cryptococcosis: an update from population-based active surveillance in 2 large metropolitan areas. Clin Infect Dis. 2003;36:789-94.

39. Mónaco LS, Tamayo Antabak N. Cryptococcosis en pacientes con SIDA: estudio de casos en el Hospital Paroissien en el periodo 1996-2007. Rev Argent Microbiol. 2008;40:218-21. 


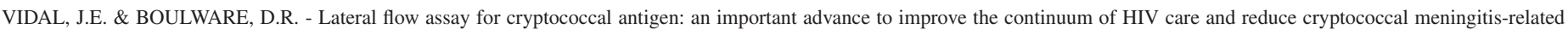
mortality. Rev. Inst. Med. Trop. Sao Paulo, 57(Suppl 19): 38-45, 2015.

40. Mora DJ, da Cunha Colombo ER, Ferreira-Paim K, Andrade-Silva LE, Nascentes GA, Silva-Vergara ML. Clinical, epidemiological and outcome features of patients with cryptococcosis in Uberaba, Minas Gerais, Brazil. Mycopathologia. 2012;173:321-7.

41. Moreira T de A, Ferreira MS, Ribas RM, Borges AS. Cryptococcose: estudo epidemiológico, laboratorial e das variedades do fungo em 96 pacientes. Rev Soc Bras Med Trop. 2006;39:255-8.

42. Musubire AK, Boulware DR, Meya DB, Rhein J. Diagnosis and management of cryptococcal relapse. J AIDS Clin Res. 2013;Suppl 3(3)pii:S3-003.

43. Oliveira JF, Greco DB, Oliveira GC, Christo PP, Guimarães MD, Oliveira RC Neurological disease in HIV-infected patients in the era of highly active antiretroviral treatment: a Brazilian experience. Rev Soc Bras Med Trop. 2006;39:146-51.

44. Park BJ, Wannemuehler KA, Marston BJ, Govender N, Pappas PG, Chiller TM. Estimation of the current global burden of cryptococcal meningitis among persons living with HIV/AIDS. AIDS. 2009;23:525-30.

45. Pasqualotto AC, Bittencourt Severo C, de Mattos Oliveira F, Severo LC. Cryptococcemia. An analysis of 28 cases with emphasis on the clinical outcome and its etiologic agent. Rev Iberoam Micol. 2004;21:143-6.

46. Pelfrey J, Bauman S. CrAg LFA: the new gold standard for diagnosis and prevention of cryptococcal disease. (cited 2015 Apr 13). Available from: www.immy.com/wpcontent/uploads/2011/12/CrAgLFA_InternationalWhitePaper_final.pdf

47. Perfect JR, Bicanic T. Cryptococcosis diagnosis and treatment: what do we know now. Fungal Genet Biol. 2014;pii:S1087-1845(14)00186-8.

48. Powderly WG, Cloud GA, Dismukes WE, Saag MS. Measurement of cryptococcal antigen in serum and cerebrospinal fluid: value in the management of AIDS-associated cryptococcal meningitis. Clin Infect Dis. 1994;18:789-92.

49. Rajasingham R, Meya DB, Boulware DR. Integrating cryptococcal antigen screening and pre-emptive treatment into routine HIV care. J Acquir Immune Defic Syndr. 2012;59:85-91.
50. Rajasingham R, Rhein J, Klammer K, Musubire A, Nabeta H, Akampurira A, et al. Epidemiology of meningitis in an HIV-infected Ugandan cohort. Am J Trop Med Hyg. 2015;92:274-9.

51. Scarborough M, Gordon SB, Whitty CJ, French N, Njalale Y, Chitani A, et al. Corticosteroids for bacterial meningitis in adults in Sub-Saharan Africa. N Engl J Med. 2007;357:2441-50

52. Tuboi SH, Schechter M, McGowan CC, Cesar C, Krolewiecki A, Cahn P, et al. Mortality during the first year of potent antiretroviral therapy in HIV-1-infected patients in 7 sites throughout Latin America and the Caribbean. J Acquir Immune Defic Syndr 2009;51:615-23.

53. Vidal JE, Penalva de Oliveira AC, Fink MC, Pannuti CS, Trujillo JR. AIDS related progressive multifocal leukoencephalopathy: a retrospective study in a referral center in São Paulo, Brazil. Rev Inst Med Trop Sao Paulo. 2008;50:209-12.

54. Vidal JE, Gerhardt J, Peixoto de Miranda EJ, Dauar RF, Oliveira Filho GS, Penalva de Oliveira AC, et al. Role of quantitative CSF microscopy to predict culture status and outcome in HIV-associated cryptococcal meningitis in a Brazilian cohort. Diagn Microbiol Infect Dis. 2012;73:68-73.

55. Vidal JE, Penalva de Oliveira AC, Dauar RF, Boulware DR. Strategies to reduce mortality and morbidity due to AIDS-related cryptococcal meningitis in Latin America. Braz J Infect Dis. 2013;17:353-62.

56. Williams D, Kiiza T, Kwizera R, Kiggundu R, Velamakanni S, Meya DB, et al. Evaluation of fingerstick cryptococcal antigen lateral flow assay in HIV-infected persons: a diagnostic accuracy study. Clin Infect Dis. 2015;61:464-7. doi: 10.1093/ cid/civ263

57. World Health Organization. Rapid advice: diagnosis, prevention, and management of cryptococcal disease in HIV-infected adults, adolescents and children. Geneva: WHO Document Production Services; 2011. p. 1-37. (cited 2012 Apr 1). Available from: www.who.int/hiv/pub/cryptococcal_disease2011 